\title{
Effects of cooling on muscle function and duration of stance phase during gait
}

\author{
Amitava Halder ${ }^{1 *}$, Chuansi Gao ${ }^{1}$, Michael Miller ${ }^{2}$ \\ From 15th International Conference on Environmental Ergonomics (ICEE XV) \\ Portsmouth, UK. 28 June - 3 July 2015
}

\section{Introduction}

Cold exposure alters muscular function. Muscle cooling influences the neuromuscular activation during maximal isometric voluntary contractions (MVC) and the amplitude of surface electromyography (sEMG) $[1,2]$. It also slows down the mechanical process during contraction [3]. The purpose of this study was to investigate the effects of local cooling in cold water at $10{ }^{\circ} \mathrm{C}$ for $20 \mathrm{~min}$ in a climate chamber on lower leg muscle activity and gait pattern.

\section{Methods}

Sixteen healthy adults (eight females), with a mean age of (SD) 27.0 (2.9) years; body mass $66.3(9.8) \mathrm{kg}$; and height 169.5 (7.8) cm participated in this experimental study. The median frequency (MF) and mean power frequency (MPF) of sEMG from tibialis anterior (TA) and gastrocnemius medialis (GM) muscles during MVC in ankle planter (PF) and dorsi-flexion (DF) against a hand-held dynamometer as well as contact times on a force plate during gait before and after cooling were measured and analysed.

\section{Results}

The MF and MPF were significantly lower $\left(\mathrm{P}<0.01^{*}\right)$ in both TA and GM muscle during MVC and in TA during gait trials after cooling. However, the frequency analysis for GM muscle showed no significant difference ( $\mathrm{p}=0.46$ and 0.06 , respectively) either in MF or MPF during walking on level surface (table 1).

Additionally, the post-cooling stance phase over the force plate was longer than pre-cooling $(\mathrm{p}=0.013)$.

\footnotetext{
* Correspondence: Amitava.Halder@design.lth.se

'Thermal Environment Laboratory, Division of Ergonomics and Aerosol Technology, Department of Design Sciences, Faculty of Engineering, Lund University, Lund, Sweden

Full list of author information is available at the end of the article
}

\section{Discussion}

The significant time difference might be caused by the cold induced MF and MPF decrease in sEMG. Our previous investigation reported that cooling increased the sEMG amplitude and produced fatigue like responses in the leg muscles [2]. Moreover, other studies showed that muscle fatigue resulted in electromechanical delay during cold exposure $[1,4]$.

\section{Conclusion}

Moderate degree and duration of cooling may affect muscle motor unit firing rates, thus shifting the sEMG spectrum to lower frequencies, therefore decreasing the leg muscle force production. The result suggests that muscle cooling can cause cold induced frequency decrease in sEMG similar to fatigue response and lead to reduced muscle performance.

\section{Authors' details \\ 'Thermal Environment Laboratory, Division of Ergonomics and Aerosol Technology, Department of Design Sciences, Faculty of Engineering, Lund University, Lund, Sweden. ${ }^{2}$ Division of Physiotherapy, Department of Health Sciences, Faculty of Medicine, Lund University, Lund, Sweden.}

Published: 14 September 2015

Table 1. The means and SD (Hz) for the MF and MPF of the TA and GM during gait and MVC trials before and after cooling ( $N=16)$

\begin{tabular}{llccc}
\hline sEMG & \multicolumn{2}{l}{ Tibialis Anterior (TA) } & \multicolumn{2}{l}{ Gastrocnemius Medialis } \\
& \multicolumn{3}{c}{ GM } \\
\hline & Pre Cooling & Post Cooling & Pre Cooling & Post Cooling \\
\hline Gait MF & $83.0 \pm 10.2^{*}$ & $69.9 \pm 9.6^{*}$ & $81.6 \pm 12.6$ & $79.3 \pm 11.1$ \\
\hline Gait MPF & $99.7 \pm 11.5^{*}$ & $82.3 \pm 11.7^{*}$ & $99.8 \pm 13.2$ & $93.2 \pm 12.4$ \\
\hline MVC MF & $87.0 \pm 9.7^{*}$ & $50.0 \pm 6.1^{*}$ & $111.7 \pm 16.7^{*}$ & $90.8 \pm 14.8^{*}$ \\
\hline MVC MPF & $100.7 \pm 10.6^{*}$ & $59.8 \pm 7.7^{*}$ & $129.1 \pm 15.3^{*}$ & $101.0 \pm 16.1^{*}$ \\
\hline
\end{tabular}




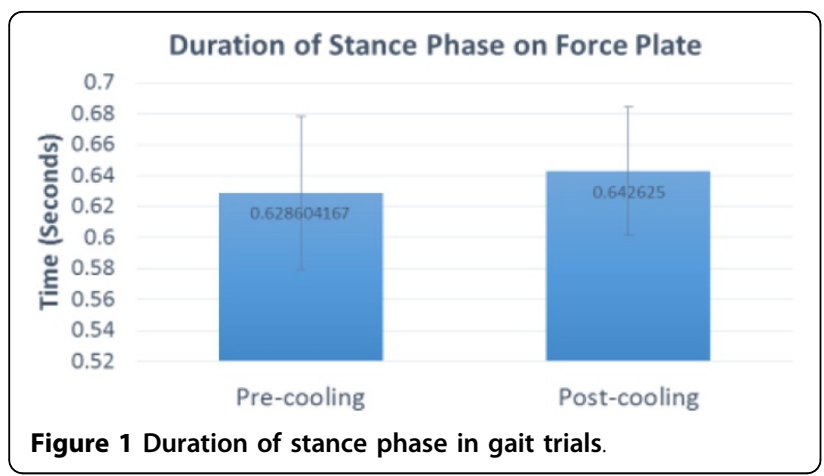

\section{References}

1. Cè E, Rampichini S, Agnello L, Limonta E, Veicsteinas A, Esposito F: Effects of temperature and fatigue on the electromechanical delay components. Muscle Nerve 2013, 47(4):566-576.

2. Halder A, Gao C, Miller M: Effects of cooling on ankle muscle maximum performances, gait ground reaction forces and electromyography. Journal of Sports Medicine 2014.

3. Drinkwater E: Effects of peripheral cooling on characteristics of local muscle. Med Sport Sci 2008, 53:5374-5388.

4. Rampichini S, Ce E, Limonta E, Esposito F: Effects of fatigue on the electromechanical delay components in gastrocnemius medialis muscle. European Journal of Applied Physiology 2014, 114(3):639-651.

doi:10.1186/2046-7648-4-S1-A47

Cite this article as: Halder et al:: Effects of cooling on muscle function and duration of stance phase during gait. Extreme Physiology \& Medicine 2015 4(Suppl 1):A47.

\section{Submit your next manuscript to BioMed Central} and take full advantage of:

- Convenient online submission

- Thorough peer review

- No space constraints or color figure charges

- Immediate publication on acceptance

- Inclusion in PubMed, CAS, Scopus and Google Scholar

- Research which is freely available for redistribution

Submit your manuscript at www.biomedcentral.com/submit
C Biomed Central 